\title{
A fauna de vertebrados do campus da Universidade Estadual de Londrina, região norte do estado do Paraná, Brasil
}

\section{The vertebrates' fauna from Universidade Estadual de Londrina campus, northern Paraná State, Brazil}

\author{
Oscar Akio Shibatta ${ }^{1}$; Wanner Galves ${ }^{1,2}$; Wanessa Priscila David do Carmo ${ }^{1}$; \\ Isaac Passos de Lima ${ }^{3}$; Edson Varga Lopes ${ }^{4}$; Reginaldo Assêncio Machado
}

\section{Resumo}

Este trabalho teve como objetivo fazer um levantamento da fauna de vertebrados do campus da Universidade Estadual de Londrina (UEL), pela compilação da literatura, com vistas a auxiliar o seu manejo e preservação. Foram registradas 250 espécies, sendo nove de peixes, 15 de anfíbios, 16 de répteis, 32 de mamíferos e 178 de aves. Duas espécies, o gato-do-mato Leopardus tigrinus e a jandaia-de-testa-vermelha Aratinga auricapillus figuram em listas de fauna ameaçada de extinção. A maioria das espécies, no entanto, não é estenóica ou endêmica da área, o que condiz com um ambiente perturbado e muito freqüentado pela população humana. $\mathrm{O}$ assoreamento do ribeirão Esperança, a redução de áreas verdes e a impermeabilização do solo podem reduzir a diversidade de espécies em médio a longo prazos.

Palavras-chave: Actinopterygii. Aves. Biodiversidade. Lissamphibia. Mammalia. Reptilia.

\begin{abstract}
This work had the objective to make a survey of vertebrates' fauna from Universidade Estadual de Londrina (UEL) campus, for the compilation of literature, in order to help its management and preservation. 250 species were identified, being nine of fish, 15 of amphibians, 16 of reptiles, 32 of mammals and 178 of birds. Two species, the gato-do-mato Leopardus tigrinus and the jandaia-da-testavermelha Aratinga auricapillus, are in the list of species threatened by extinction. Most species, however, are not stenoecious or endemic to the area, which corresponds to an environment under stress and often visited by humans. Despite UEL's rich diversity of wild animals, the burying of stream Esperança, the reduction of green areas and waterproofing of the ground can reduce de diversity of species in a medium or long term.
\end{abstract}

Key words: Actinopterygii. Birds. Biodiversity. Lissamphibia. Mammalia. Reptilia.

\footnotetext{
1 Museu de Zoologia, Depto. de Biologia Animal e Vegetal, Universidade Estadual de Londrina - Londrina, PR. E-mail: shibatta@, uel.br

2 Programa de Pós-Graduação em Ciências Biológicas, Centro de Ciências Biológicas, Universidade Estadual de Londrina Londrina, PR

3 Programa de Pós-Graduação em Biologia Animal, Instituto de Biologia, Universidade Federal Rural do Rio de Janeiro - Rio de Janeiro, RJ.

4 Programa de Pós-Graduação em Ecologia de Ecossistemas Aquáticos Continentais - PEA, Universidade Estadual de Maringá Maringá, PR

5 Laboratório de Herpetologia, Campus Floresta, Universidade Federal do Acre - Cruzeiro do Sul, AC.
} 


\section{Introdução}

Vertebrados constituem um grupo diversificado de animais, com aproximadamente 57.672 espécies viventes, distribuídas tradicionalmente nas seguintes classes: Myxini (70 espécies), Cephalaspidomorphi (38 espécies), Chondrichthyes (970 espécies), Sarcopterygii (8 espécies) e Actinopterygii (26.891 espécies) (NELSON, 2006), Amphibia (6.091 espécies) (FROST, 2004), Reptilia (8.240 espécies) (UETZ, 2007), Mammalia (5.416 espécies) (WILSON, REEDER, 2005) e Aves (9.948 espécies) (ZOONOMEN, 2007). Apesar desses agrupamentos nem sempre representarem linhagens monofiléticas (e.g. Reptilia), eles serão utilizados neste trabalho, por serem popularmente conhecidos.

A riqueza de vertebrados no Brasil é considerada uma das maiores do mundo (LEWINSON; PRADO, 2002), ocorrendo em todos os ecossistemas. A Mata Atlântica é considerada um dos ecossistemas mais ricos em espécies animais e vegetais. Segundo Ab'Saber (1977), a região norte do Paraná encontra-se dentro desse domínio, o qual enquadra no grupo geomorfológico tropical atlântico ou, como é conhecido simbolicamente, "domínio de mares de morros", com um subdomínio de Chapadões Florestados. A grande biodiversidade dessa região, no entanto, está ameaçada porque a floresta contínua cedeu lugar a uma paisagem em mosaico, composta por remanescentes relativamente isolados entre si. No município de Londrina, os remanescentes florestais raramente ultrapassam 100 ha de área, somando apenas 2 a 4\% da cobertura original (INSTITUTO PARANAENSE DE DESENVOLVIMENTO ECONÔMICO E SOCIAL - IPARDES, 1993). O campus da Universidade Estadual de Londrina (UEL) localiza-se em uma área de transição, entre uma região intensamente urbanizada e a zona rural, apresentando vegetação arbórea entremeada por edificações, áreas de agricultura, estação de piscicultura e um pequeno remanescente relativamente preservado de Floresta Estacional Semidecidual.
Parece razoável supor que remanescentes florestais inseridos em uma matriz totalmente urbana, densamente povoada, possivelmente são mais perturbados do que aqueles mais afastados de aglomerações humanas e/ou inseridos em uma matriz de vegetação mais diversificada. Além disso, mesmo dentro de uma matriz urbana, um remanescente florestal pode apresentar maior proporção de representantes da fauna original do que áreas desflorestadas. Entretanto, essas estimativas de perda da diversidade se tornam meramente especulativas se não estiverem embasadas em dados históricos de levantamentos periódicos da fauna. Daí a importância deste trabalho, que em primeira instância constituirá um registro que possibilitará comparar a riqueza de espécies no campus ao longo do tempo.

Alguns levantamentos de vertebrados foram realizados no campus, mas eles estão dispersos em dissertações, monografias de bacharelado ou literatura especializada, nem sempre acessíveis ao público em geral. Este é o primeiro trabalho que se propõe a fazer uma análise integrada da riqueza de espécies de vertebrados da UEL, com o objetivo de contribuir para o correto manejo da área e preservação de suas espécies.

\section{Material e métodos}

O campus da Universidade Estadual de Londrina (UEL), também conhecido como campus Perobal, foi fundado em 28 de janeiro de 1970, e está situado na periferia da cidade, a sudoeste de Londrina, no km 380 da Rodovia Celso Garcia Cid. O marco do IBGE na UEL possui as seguintes coordenadas: $23^{\circ} 19^{\prime} 19^{\prime}$ 'S e $51^{\circ} 12^{\prime} 04^{\prime \prime} \mathrm{W}$. A área total é de $2.226 .013 \mathrm{~m}^{2}$, com área construída de 181.675,82 $\mathrm{m}^{2}$, o que corresponde a apenas $8,2 \%$ do total com áreas impermeabilizadas por construções (salas, calçadões, ruas, estacionamentos, quadras, etc.). A área construída se concentra na região norte do campus, enquanto que na região centro-sul 
as características são eminentemente agrícolas e constituídas pelo Campo Experimental, Estação de Piscicultura (EPUEL) e Fazenda Escola. Esta possui aproximadamente $726.000 \mathrm{~m}^{2}$, sendo uma área aberta e de grande influência antrópica. A UEL tem uma grande variedade de espécies vegetais nativas e introduzidas que contribuem para o fornecimento de alimento e/ou abrigo a várias espécies de animais, como, por exemplo, o abacateiro (Persea americana Mill.), a amendoeira (Terminalia catappa L.), a amoreira (Morus nigra L.), a canela (Cinnamomum zeylanicum Ness), o coquinho (Syagrus romanzoffiana (Cham.) Glassman), as figueiras (Ficus spp.), a goiabeira (Psidium gajava L.), o guapuruvu (Schizolobium parahyba (Vell.) S. F. Blake), os ipês (Tabebuia spp.), a jaqueira (Artocarpus sp.), a magnóliaamarela (Magnolia champaca (L.) Baill ex Pierre), a mangueira (Mangifera indica L.), o palmiteiro (Euterpe edulis Mart.), a peroba (Aspidosperma polyneuron Müll. Arg.) e a pitangueira (Eugenia uniflora L.).As áreas de jardins, gramados e canteiros possuem várias plantas arbustivas como a azaléia (Rhododendron sp.) e o hibiscus (Hibiscus sp.), que constituem um hábitat importante para animais que preferem o estrato inferior de florestas. Na região sudoeste encontra-se uma área com vegetação nativa preservada conhecida como Horto Florestal. Trata-se de um remanescente de floresta estacional semidecidual, com área de $57.500 \mathrm{~m}^{2}$, que somados a uma área de mata particular contígua, constituem uma área de $120.000 \mathrm{~m}^{2}$, com uma vegetação heterogênea. Entre outras famílias vegetais que fazem parte do Horto Florestal, podem ser citadas: Moracea, Piperaceae, Solanaceae e Cecropiacaea. Uma pequena área ao lado do Horto, denominada Campo Experimental, é utilizada para pomares e hortas experimentais, onde há relativa influência antrópica, além de eventuais entulhos de madeira e outros materiais utilizados pelos servidores. Logo abaixo do Horto Florestal, encontra-se a Estação de Piscicultura da UEL, com uma área de $10.000 \mathrm{~m}^{2}$ sendo $410 \mathrm{~m}^{2}$ de área edificada. $\mathrm{O}$ córrego Cebolão surge dentro do Horto Florestal e deságua no ribeirão Esperança, este por sua vez deságua no ribeirão Cafezal que se une ao ribeirão Três Bocas e juntamente com o ribeirão do Cerne, afluem ao rio Tibagi em sua margem esquerda. $\mathrm{O}$ ribeirão Esperança, um riacho urbano alterado, é um afluente de terceira ordem do baixo rio Tibagi, e é o principal curso de água natural da UEL. Segundo Vieira e Shibatta (2007), o trecho que se localiza na UEL é o ponto do ribeirão com maior profundidade, com média de $53 \mathrm{~cm}$. Possui um leito bastante argiloso e em alguns pontos mais rasos, perto das margens, é possível notar a formação de bancos de terra devido ao assoreamento. A figura 1 representa esquematicamente o campus da UEL.

Para o levantamento de espécies foi utilizada a literatura, sendo a lista de espécies de Actinopterygii (peixes) obtida de Vieira e Shibatta (2007), de coletas realizadas no período de março a novembro de 2005. A lista de Lissamphibia (anfíbios) e Reptilia (répteis) foi obtida de Machado (1996) e Machado et al. (1999), cujos dados foram coletados no período de agosto de 1995 a abril de 1996, sendo os anfíbios classificados conforme Frost (2004), com modificações de Baldissera Júnior, Caramaschi e Haddad (2004), Faivovich et al. (2005) e Frost et al. (2006), e os répteis conforme a Sociedade Brasileira de Herpetologia - SBH (2005). As espécies de Mammalia foram obtidas a partir de trabalhos realizados com morcegos no campus por Muller e Reis (1992), Lima (1994), Reis, Lima e Peracchi (2002) e Reis et al. (2003), no período de 1991 a 2003 e comunicações pessoais de Nélio Roberto dos Reis, Vlamir Rocha e Gisele A. S. Doratti dos Santos. A lista de Aves foi obtida em Gimenes e Anjos (2000) e Lopes e Anjos (2006), de coletas de dados realizadas no período de setembro de 1996 a setembro de 1997 e de janeiro de 2001 a dezembro de 2002, respectivamente. A seqüência taxonômica segue o Comitê Brasileiro de Registros Ornitológicos (2006) e as categorias tróficas foram baseadas em Del Hoyo, Elliott e Sargatal (19922005), Sick (1997) e observações de um dos autores (EVL) em campo. 


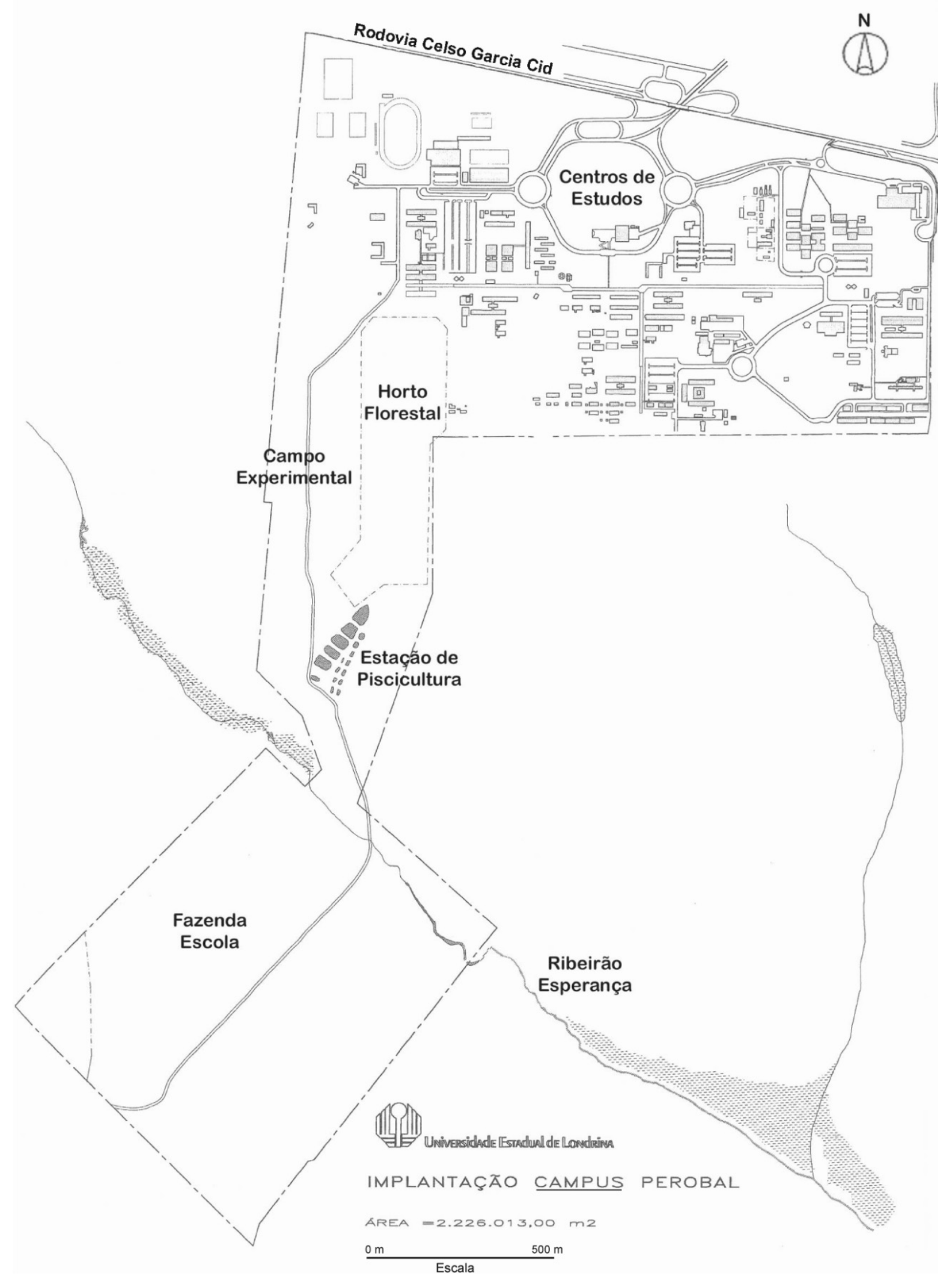

Figura 1. Campus da Universidade Estadual de Londrina (imagem elaborada pela Diretoria de Planejamento e Desenvolvimento Físico da UEL no ano de 2007). Hachuras ao longo do ribeirão Esperança representam áreas úmidas. 


\section{Resultados e discussão}

AUEL apresentou uma riqueza de 250 espécies de vertebrados, sendo nove de peixes, 15 de anfíbios, 16 de répteis, 32 de mamíferos e 178 de aves. Portanto, o grupo com maior número de espécies foi o de aves, que representou $70,4 \%$ da diversidade total. A seguir apresentam-se os resultados e discussões de cada grupo taxonômico por ordem crescente de riqueza de espécies na UEL.

\section{Ictiofauna (Actinopterygii, nove espécies)}

Vieira e Shibatta (2007) registraram 12 espécies de peixes no ribeirão Esperança, com apenas três espécies (o canivetinho Characidium zebra, a tuvira Gymnotus carapo e o camboja Callichthys callichthys) não ocorrendo no trecho referente à UEL (Tabela 1). Entre os cinco trechos estudados por aqueles autores, o da UEL foi o que apresentou maior riqueza de espécies e a menor dominância, refletindo sua importância biológica no contexto dessa micro-bacia. Essas espécies ainda representam as cinco ordens de peixes comuns a outros riachos da bacia do Tibagi, como pode ser verificado em Shibatta et al. (2002).

Em relação às espécies introduzidas, foram encontradas Poecilia reticulata, lebiste, e Xiphophorus hellerii, peixe-espada, em elevada abundância de exemplares, o que pode indicar que o ambiente esteja sofrendo algum distúrbio ambiental (ARAÚJO, 1998). O lebiste foi o mais abundante do trecho, com 437 exemplares capturados e o peixeespada foi o quarto, com 43 exemplares (VIEIRA; SHIBATTA, 2007). Estas duas espécies podem ter sido introduzidas por aquariofilistas que descartaram seus exemplares.

Entre as espécies nativas, destaca-se o cascudo Hypostomus ancistroides que foi a segunda espécie mais abundante, com 147 exemplares capturados (VIEIRA; SHIBATTA, 2007). A terceira espécie mais abundante foi o acará Geophagus brasiliensis, com 64 exemplares.
Um fator importante e fundamental para o estabelecimento de uma determinada espécie em um local é a disponibilidade de alimentos (BENNEMANN; SHIBATTA; GARAVELO, 2000). Através dos grupos tróficos identificados, é possível inferir quais são os recursos disponíveis para as populações e fazer uma avaliação do ambiente amostrado (CASATTI, 2002; OLIVEIRA; BENNEMANN, 2005). No caso do ribeirão Esperança, foram encontrados pelo menos quatro grupos tróficos, conforme descrição na literatura. $\mathrm{O}$ lambari Astyanax altiparanae é uma espécie onívora, com dieta composta por uma grande quantidade de itens, com preferência por larvas de insetos (DUKE ENERGY, 2003; HAHN; FUGI; ANDRIAN, 2004). Esta espécie pode ser utilizada comercialmente como iscas na pesca esportiva e também na culinária; vive em cardumes, os quais podem realizar pequenas migrações em período reprodutivo (DUKE ENERGY, 2003; GRAÇA; PAVANELLI, 2007), ou na busca de alimento. Ela foi encontrada em locais de remansos, pois forrageia em meio à coluna d'água, e em locais com vegetação ripária (VIEIRA; SHIBATTA, 2007). O lambari Bryconamericus iheringii, também onívoro, apresenta uma tendência a se alimentar de itens de origem vegetal e algas (HAHN; FUGI; ANDRIAN, 2004). Outra espécie considerada onívora é o bagre Rhamdia quelen que se alimenta de vários itens, mas há uma preferência por peixes (DUKE ENERGY, 2003; HAHN; FUGI; ANDRIAN, 2004). A traíra Hoplias malabaricus também apresenta preferência alimentar por peixes (AGOSTINHO et al., 1997). Outra espécie carnívora é o mussum Synbranchus marmoratus, mas com dieta composta principalmente por larvas de insetos (DUKE ENERGY, 2003; CASATTI; LANGEANI; CASTRO, 2001). Poecilia reticulata e Xiphophorus hellerii são espécies que se alimentam preferencialmente de larvas de insetos (LUZAGOSTINHO et al., 2006), porém se adaptam facilmente a locais degradados, onde sua dieta é composta basicamente por detritos (OLIVEIRA; BENNEMANN, 2005; BENNEMANN 
comunicação pessoal). Geophagus brasiliensis é tipicamente detritívora e tem o hábito de abocanhar o substrato à procura de alimento (COMPANHIA ENERGÉTICA DE MINAS GERAIS - CEMIG; CENTRO TECNOLÓGICO DE MINAS GERAIS - CETEC, 2000). Hypostomus ancistroides é considerada detritívora (DUKE ENERGY, 2003; HAHN; FUGI; ANDRIAN, 2004), uma vez que se alimenta principalmente do perifiton aderido às rochas e de detritos do substrato. Sendo assim, a disponibilidade de recursos alimentares para o trecho em questão é suficiente para manter uma cadeia com os seus principais componentes, o que pode explicar a maior riqueza de espécies encontrada nesse trecho do ribeirão Esperança. Algumas espécies, no entanto, apresentam plasticidade trófica, e devido à pequena disponibilidade de um determinado recurso, podem optar por outro.

Vieira e Shibatta (2007) apontam como principais sinais de degradação do ribeirão Esperança, o desmatamento de suas margens, a construção de condomínios residenciais ao longo do seu curso e o conseqüente assoreamento de seu leito.

Tabela 1. Nome popular e categoria trófica das espécies de peixes Actinopterygii do campus da Universidade Estadual de Londrina, Londrina, PR.

\begin{tabular}{|c|c|c|}
\hline Táxon & Nome popular & Categoria trófica \\
\hline \multicolumn{3}{|l|}{ Classe Actinopterygii } \\
\hline \multicolumn{3}{|l|}{ Ordem Characiformes } \\
\hline \multicolumn{3}{|l|}{ Família Characidae } \\
\hline Astyanax altiparanae Garutti \& Britski, 2000 & Lambari, tambiú & Onívoro \\
\hline Bryconamericus iheringii (Boulenger, 1887) & Lambari & Onívoro \\
\hline \multicolumn{3}{|l|}{ Família Erythrinidae } \\
\hline Hoplias malabaricus (Bloch, 1794) & Traíra & Carnívoro \\
\hline \multicolumn{3}{|l|}{ Ordem Siluriformes } \\
\hline \multicolumn{3}{|l|}{ Família Loricariidae } \\
\hline Hypostomus ancistroides (Ihering, 1911) & Cascudo & Detritívoro \\
\hline \multicolumn{3}{|l|}{ Família Heptapteridae } \\
\hline Rhamdia quelen (Quoy \& Gaimard, 1824) & Bagre & Onívoro/Piscívoro \\
\hline \multicolumn{3}{|l|}{ Ordem Synbranchiformes } \\
\hline \multicolumn{3}{|l|}{ Família Synbranchidae } \\
\hline Synbranchus marmoratus Bloch, 1795 & Mussum & Carnívoro \\
\hline \multicolumn{3}{|l|}{ Ordem Perciformes } \\
\hline \multicolumn{3}{|l|}{ Família Cichlidae } \\
\hline Geophagus brasiliensis (Quoy \& Gaimard, 1824) & acará, acará-de-topete & Detritívoro \\
\hline \multicolumn{3}{|l|}{ Ordem Cyprinodontiformes } \\
\hline \multicolumn{3}{|l|}{ Família Poeciliidae } \\
\hline Poecilia reticulata Peters, 1859 & Lebiste & Insetívoro/ Detritívoro \\
\hline Xiphophorus hellerii Heckel, 1848 & Peixe-espada & Insetívoro/ Detritívoro \\
\hline
\end{tabular}


Herpetofauna (31 espécies, 15 de Lissamphibia e 16 de Reptilia)

A herpetofauna da UEL está representada por 15 espécies de anfíbios, distribuídas em cinco famílias, e 16 de répteis, distribuídas em sete famílias (Tabela 2). Devido ao avanço das ocupações humanas na região e a conseqüente destruição de hábitats, a estrutura ambiental do campus ainda funciona como refúgio para este grupo. Existe concentração de ocorrências em áreas menos destruídas, tais como a região do Horto Florestal, da EPUEL, do ribeirão Esperança e da Fazenda Escola. Entretanto, várias espécies de anfíbios e de répteis deslocam-se pelas diferentes estruturas do campus sendo, por muitas vezes, mortos no processo.

Os anfíbios do campus são encontrados em diversos ambientes, tais como serapilheira, sob ou sobre troncos, cascas soltas de árvore, brejos, dentro e na borda de riachos (inclusive na vegetação ali presente), buracos no chão, superfície do solo e dentro de bromélias em cujas rosetas podem acumular quantidade de água suficiente para a moradia destes animais. Entretanto nenhuma espécie é estenóica florestal, ou seja, todas as espécies podem ser encontradas em ambientes abertos e todas foram observadas na Estação de Piscicultura (MACHADO, 1996), o que mostra que a presença destes animais está relacionada com um reservatório de água, pois possuem um estágio larval aquático.

Desta forma, cinco modos reprodutivos em anfíbios (sensu DUELLMAN; TRUEB, 1986, revisado e ampliado por HADDAD; PRADO, 2005, ver também MACHADO; BERNARDE, 2003) são encontrados no campus: (Modo 4) Hypsiboas faber com ovos e primeiros estágios larvais em pequenas piscinas escavadas pelo macho nas bordas da poça e, com a chegada das chuvas, ocorre inundação da piscina e os girinos exotróficos terminam o desenvolvimento na poça; (Modo 11) Physalaemus cuvieri e L. ocellatus depositam seus ovos em ninhos de espuma flutuantes e os girinos exotróficos terminam o desenvolvimento na água; (Modo 13)
Leptodactylus labyrinthicus deposita seus ovos em ninhos flutuantes de espuma em piscinas construídas, onde ocorre inundação e os girinos exotróficos terminam o desenvolvimento; (Modo 30) L. fuscus reproduz-se em tocas escavadas pelo macho nas áreas brejosas, próximo a poças temporárias, onde deposita os ovos em ninho de espuma, os primeiros estágios larvais aí permanecem e, na chegada das chuvas, os girinos exotróficos completam o desenvolvimento na água da poça; e (Modo 1) todas as demais espécies depositam seus ovos diretamente em ambiente aquático lêntico onde os girinos exotróficos se desenvolvem.

Segundo Machado (1996), apenas quatro espécies de anfíbios (Chaunus schneideri, Scinax fuscovarius, $H$. faber e L. fuscus) ocorreram nas áreas construídas. Porém, como estes ambientes não oferecem condições reprodutivas, os registros são considerados acidentais. Por outro lado as formações vegetais locais podem servir de abrigo contra predadores e para proteção fisiológica, evitando a perda de água por evaporação. Pode servir, também, como fonte de recurso alimentar, para dispersão e como sítio de vocalização, principalmente no caso dos hilídeos que são arborícolas em sua maioria.

No campus, os anfíbios também são predadores e têm papel como presas, uma vez que a riqueza de anuros presentes no local confere importante recurso alimentar. Machado (1996) registrou a predação de anuros pelas serpentes Bothrops jararaca (jararaca), Thamnodynastes strigatus (jararaquinha) e Liophis miliaris (cobra-d'água) e predação pelas aves Guira guira (anu-branco), Athene cunicularia (corujaburaqueira) e Pitangus sulphuratus (bem-te-vi).

Nenhuma das espécies de anfíbios do campus pode ser considerada perigosa ao homem. No entanto, elas são caracterizadas por possuírem toxinas em sua pele (DUELLMAN; TRUEB, 1986). Desta forma, se porventura ocorrer o contato manual com alguns destes animais, é importante tomar cuidado para não tocar a boca ou os olhos, pois em algumas espécies estas toxinas são irritantes para as mucosas 
humanas. A espécie Leptodactylus labyrinthicus, conhecida como rã-pimenta por causa da ardência que provoca em mucosas expostas, apesar de não ser encontrada com freqüência, foi avistada por seguranças da EPUEL (MACHADO, 1996).

De forma geral existe uma grande lacuna no que tange o conhecimento sobre os hábitos alimentares dos anfíbios. Poucas espécies foram sistematicamente estudadas e os conhecimentos disseminados estão reduzidos a comentários esparsos em literaturas diversas. Basicamente as espécies presentes no Campus da UEL alimentam-se de artrópodes de pequeno porte, entretanto aquelas espécies de anuros de maior porte podem incluir em sua dieta também algumas formas de vertebrados, como é o caso de Chaunus schneideri, Hypsiboas faber, Leptodactylus ocellatus e L. labyrinthicus (Tabela 2).

Segundo Machado (1996), os répteis podem ocorrer tanto na água como em terra firme (terrestres propriamente ditos, subterrâneos, e arborícolas), sendo encontrados em locais como pasto alto em horas de sol quente, pilhas de lenha dentro do mato, raízes velhas de troncos mortos e semi-ocados, margens de água, pedras, troncos semi-emersos, folhiço da mata, além de encontros acidentais nas áreas construídas.

As duas espécies de lagartos do campus, Hemidactylus mabouia e Tupinambis merianae são conhecidas por habitarem áreas antrópicas. A primeira de forma preferencial e a segunda de maneira oportunista. Segundo Zamprogno e Teixeira (1998), H. mabouia alimenta-se de forma generalizada de artrópodos, tendo um papel de controle destes organismos nas habitações. Já $T$. merianae, alimenta-se de artrópodos, pequenos vertebrados e frutos (COLLI; PERES JÚNIOR; CUNHA, 1998) podendo também ser um bom dispersor de sementes (CASTRO; GALETTI, 2004). A espécie H. mabouia, conhecida por lagartixa de parede, foi possivelmente introduzida no Brasil por ação humana, transportada por navios com escravos africanos ou com imigrantes europeus (GOELDI, 1902).

Segundo Bernarde e Machado (2003), oito das 11 espécies de serpentes que ocorreram no campus podem incluir anfíbios, aves ou mamíferos na sua dieta. Bothrops jararaca (comendo anfíbios quando jovens e roedores quando adultas), Chironius bicarinatus (anfíbios), Helicops modestus (peixes e anfíbios, principalmente girinos), L. miliaris (peixes, anfíbios e lagartos), L. poecilogyrus (anfíbios), Mastigodryas bifossatus (anfíbios e roedores), Phylodrias olfersii (anfíbios, lagartos, roedores e aves) e Thamnodynastes strigatus (peixes, anfíbios, lagartos e roedores). Dipsas indica e Sybinomorphus mikanii alimentam-se de moluscos, porém a primeira é arborícola e a segunda é terrestre e, portanto, podem ser freqüentemente encontradas em ambientes úmidos de floresta e área aberta, respectivamente. Ainda Lyotyphlops beui alimentase de artrópodos e Oxyrhopus guibei de lagartos e roedores.

Dentre as serpentes do campus, quatro podem provocar envenenamento. Uma espécie solenóglifa (com presas grandes e ocas situadas na região anterior da boca), a jararaca ( $B$. jararaca), possui a cabeça triangular e dorso marrom acinzentado com figuras em forma de " $\Lambda$ " distribuído na lateral do corpo. Três outras espécies são opistóglifas (possuem presas aumentadas e sulcadas na região posterior da boca), como a falsa-coral (Oxyrhopus guibei), a cobra-verde (Philodryas olfersii) e a jararaca ou cobra-flecha (Thamnodynastes strigatus). A falsa-coral possui o padrão de faixas vermelhas, pretas e brancas que não se completam no ventre, mas ultrapassam seu limite lateral, ao contrário da coral verdadeira, onde as faixas se completam no ventre. É uma serpente terrícola com atividade predominantemente crepuscular, podendo ser ativa também durante o dia.

A existência das espécies de anfíbios e répteis na UEL só é possível devido à riqueza de estruturas 
ambientais conferida pelo serviço de jardinagem, pela presença do Horto Florestal, da Fazenda Escola e recursos hídricos locais que fornecem o hábitat e os recursos alimentares. Mesmo assim, a UEL não apresenta espécies herpetofaunísticas endêmicas, estenóicas e raras, o que demonstra um alto grau de alteração ambiental. Entretanto, ao menos 15 espécies de anfíbios e 16 de répteis ainda encontram no campus as condições necessárias para aí permanecerem.

Tabela 2. Nome popular e categoria trófica das espécies de Lissanphibia e Reptilia do campus da Universidade Estadual de Londrina, Londrina, PR. Categorias tróficas presumidas estão indicadas com (?)

\begin{tabular}{|c|c|c|}
\hline Táxon & Nome popular & Categoria tró \\
\hline \multicolumn{3}{|l|}{ CLASSE LISSAMPHIBIA } \\
\hline \multicolumn{3}{|l|}{ Ordem Anura } \\
\hline \multicolumn{3}{|l|}{ Família Bufonidae } \\
\hline Chaunus abei (Baldissera-Jr, Caramschi \& Haddad, 2004) & Sapinho & (?) Insetívoro \\
\hline Chaunus schneideri (Werner, 1894) & Sapo-cururu & Carnívoro \\
\hline \multicolumn{3}{|l|}{ Família Hylidae } \\
\hline Dendropsophus minutus (Peters, 1872) & Pererequinha & (?) Insetívoro \\
\hline Dendropsophus nanus (Boulenger, 1889) & Pererequinha & Insetívoro \\
\hline Hypsiboas albopunctatus (Spix, 1824) & Perereca-cabra & Desconhecido \\
\hline Hypsiboas faber (Wied-Neuwied, 1821) & Sapo-ferreiro & Carnívoro \\
\hline Hypsiboas prasinus (Burmeister, 1856) & Perereca & Desconhecido \\
\hline Hypsiboas raniceps Cope, 1862 & Perereca-cabra & (?) Insetívoro \\
\hline Scinax fuscovarius (A.Lutz, 1925) & Perereca-de-banheiro & (?) Insetívoro \\
\hline Scinax perereca Pombal, Haddad \& Kasahara, 1995 & Perereca & (?) Insetívoro \\
\hline \multicolumn{3}{|l|}{ Família Leiuperidae } \\
\hline Physalaemus cuvieri Fitzinger, 1826 & Rã-cachorro & (?) Insetívoro \\
\hline \multicolumn{3}{|l|}{ Família Leptodactylidae } \\
\hline Leptodactylus ocellatus (Linnaeus, 1758) & Rã-manteiga ou paulistinha & Carnívoro \\
\hline Leptodactylus fuscus (Schneider, 1799) & Rã-assobiadora & Desconhecido \\
\hline Leptodactylus labyrinthicus (Spix, 1824) & Rã-pimenta ou jia & Carnívoro \\
\hline \multicolumn{3}{|l|}{ Família Microhylidae } \\
\hline Elachistocleis bicolor (Guérin-Méneville, 1838) & Rã-guardinha & Insetívoro \\
\hline \multicolumn{3}{|l|}{ CLASSE REPTILIA } \\
\hline \multicolumn{3}{|l|}{ Ordem Testudinata } \\
\hline \multicolumn{3}{|l|}{ Subordem Pleurodira } \\
\hline \multicolumn{3}{|l|}{ Família Chelidae } \\
\hline Phrynops geoffroanus (Schweigger, 1814) & Tartaruga, cágado & Onívoro \\
\hline \multicolumn{3}{|l|}{ Ordem Squamata } \\
\hline \multicolumn{3}{|l|}{ Subordem Amphisbaenia } \\
\hline \multicolumn{3}{|l|}{ Família Amphisbaenidae } \\
\hline Amphisbaena mertensi Strauch, 1881 & $\begin{array}{l}\text { Cobra-de-duas-cabeças ou } \\
\text { cobra-cega }\end{array}$ & (?) Insetívoro \\
\hline \multicolumn{3}{|l|}{ Subordem Sauria } \\
\hline Hemidactylus mabouia (Moreau-de-Jonnès, 1818) & Lagartixa-de-parede & (?) Insetívoro \\
\hline \multicolumn{3}{|l|}{ Família Teiidae } \\
\hline \multicolumn{3}{|l|}{ Subordem Serpentes } \\
\hline Família Anomalepididae & & \\
\hline Lyotyphlops beui (Amaral, 1924) & $\begin{array}{l}\text { Cobra-de-duas-cabeças ou } \\
\text { cobra-cega }\end{array}$ & (?) Insetívoro \\
\hline
\end{tabular}




\begin{tabular}{|c|c|c|}
\hline Táxon & Nome popular & Categoria trófica \\
\hline \multicolumn{3}{|l|}{ Família Colubridae } \\
\hline Chironius bicarinatus (Wied-Neuwied, 1820) & Cobra-cipó ou cobra-verde & Carnívoro \\
\hline Dipsas indica Laurenti, 1768 & Dormideira ou come-lesma & Moluscívoro \\
\hline Helicops modestus Gunther, 1861 & Cobra-d'água & Carnívoro \\
\hline Liophis miliaris (Linnaeus, 1758) & $\begin{array}{l}\text { Cobra-d'água ou cobra-de- } \\
\text { capim }\end{array}$ & Carnívoro \\
\hline Liophis poecilogyrus Wied-Neuwied, 1824 & Cobra-d'água & Carnívoro \\
\hline Mastigodryas bifossatus (Raddi, 1820) & Jararacuçu-do-brejo & Carnívoro \\
\hline Oxyrhopus guibei Hoge \& Romano, 1977 & Falsa-coral & Carnívoro \\
\hline Philodryas olfersii (Lichtenstein, 1823) & Cobra-verde & Carnívoro \\
\hline Sibynomorphus mikanii (Schlegel, 1837) & Dormideira, jararaquinha & Carnívoro \\
\hline Thamnodynastes strigatus (Gunther, 1858) & Jararaca ou cobra-flecha & Carnívoro \\
\hline \multicolumn{3}{|l|}{ Família Viperidae } \\
\hline Bothrops jararaca (Wied-Neuwied, 1824) & Jararaca & Carnívoro \\
\hline
\end{tabular}

\section{Mastofauna (32 espécies)}

Um dos fatores predominantes para determinar a existência de espécies de mamíferos no campus da UEL está relacionado diretamente ao tipo de alimento encontrado na área do campus além da restrição do espaço físico e por se tratar de uma área urbana. Aqui as espécies não voadoras estão restritas ao Horto Florestal, como no caso da cuícade-cauda-grossa Lutreolina crassicaudata que vive em áreas alagadas, provavelmente ocupando a porção sul do Horto, onde estão os tanques de piscicultura (Fig. 1), pois sua dieta consiste de pequenos mamíferos, aves, répteis, peixes, ovos, insetos e frutos (MONTEIRO-FILHO; DIAS, 1990; CÁCERES; GHIZONI JÚNIOR; GRAIPEL, 2002; SANTORI et al., 2005; ROSSI; BIANCONI; PEDRO, 2006). Outras espécies podem até utilizar áreas mais arborizadas do Campus, como é o caso do macaco-prego Cebus nigritus (SILVEIRA, 2003). Quando analisado o hábito alimentar das 32 espécies de mamíferos da UEL, percebe-se que a maioria das espécies tem como base da sua dieta os frutos (frugívoros), os insetos (insetívoros) e partes vegetais (folhas, caules e ramos) (Tabela 3 ).

Os morcegos contribuem na polinização e dispersão de sementes de diversas plantas no caso dos fitófagos, além dos insetívoros que controlam populações de insetos, muitos deles prejudiciais ao homem (LIMA, 1994; UIEDA, 1999). De acordo com Pedro e Passos (2001) cerca de 20\% das espécies de morcegos no Brasil adaptam-se aos ambientes modificados pelo homem ou a ambientes urbanos. A quantidade de espécies de morcegos insetívoros em áreas urbanas está relacionada com a oferta dos insetos que são atraídos pela iluminação pública (RYDELL, 1992); já os frugívoros encontram alimento nas áreas verdes com árvores frutíferas. Estes morcegos também utilizam as construções humanas como forma de abrigo, pois muitas delas atuam como cavernas artificiais (BREDT et al., 1996; PEDRO, 1998; REIS; LIMA; PERACCHI, 2002).

As espécies da ordem Carnivora geralmente requerem grandes áreas de vida, principalmente as de grande porte. As três espécies de carnívoros encontrados são de pequeno porte: o gato-mourisco Puma yagouaroundi, o gato-do-mato-pequeno Leopardus tigrinus e o furão-pequeno Galictis cuja e provavelmente em reduzido número de indivíduos, utilizando o Horto Florestal como abrigo onde buscam outros mamíferos, lagartos e aves como forma de alimento. É importante ressaltar que $L$. tigrinus, o menor felino brasileiro (CHEIDA et al., 2006), é considerado vulnerável de extinção no Paraná (MARGARIDO; BRAGA, 2004). 
A população de macaco-prego está isolada no Horto Florestal, uma ilha de vegetação na qual seus inimigos naturais não estão presentes, o que tem levado ao aumento da população. Isso pode causar problemas não só de consangüinidade, levando a doenças congênitas e comprometendo o futuro destes grupos isolados, como também resultar na predação excessiva de ovos e filhotes de aves que ocorrem nesse fragmento. A conseqüente superpopulação tem levado esses animais a saquear as instalações do campus circunvizinhas à mata para a procura de alimentos, principalmente durante o inverno. Outra situação que merece atenção é que ao procurarem por alimentos fora da mata, os primatas entram em contato direto com pessoas que podem sofrer mordidas ao tentarem alimentá- los. Em 1991 quando a população de Cebus era de 21 indivíduos, 14 desses animais foram remanejados com o objetivo de conter o aumento populacional (ROCHA, 1992). Em dezembro de 2002, Silveira (2003) contabilizou 18 indivíduos, já detectando problemas populacionais. Ou seja, 15 anos após o primeiro manejo, a população pode estar necessitando de um novo manejo. Uma forma de mitigar rapidamente o aumento da população seria esterilizar o macho Alfa (dominante) do grupo por vasectomia, o que impediria a fertilização das fêmeas sem comprometer o seu comportamento de liderança. Entretanto, uma solução mais adequada seria a implementação de um corredor florestal, para que o excedente de indivíduos pudesse se dispersar para a mata ciliar do ribeirão Esperança.

Tabela 3. Nome popular e categoria trófica das espécies de Mammalia do campus da Universidade Estadual de Londrina, Londrina, PR.

\begin{tabular}{|c|c|c|}
\hline Taxón & Nome popular & Categoria trófica \\
\hline \multicolumn{3}{|l|}{ Classe Mammalia } \\
\hline \multicolumn{3}{|l|}{ Ordem Carnivora } \\
\hline \multicolumn{3}{|l|}{ Família Felidae } \\
\hline Puma yagouaroundi (E. Geoffory Saint-Hilare, 1803) & Jaguarundi, gato-mourisco & Carnívoro \\
\hline Leopardus tigrinus (Schreber, 1775) & Gato-do-mato-pequeno & Carnívoro \\
\hline \multicolumn{3}{|l|}{ Família Canidae } \\
\hline Cerdocyon thous (Linnaeus, 1766) & Cachorro-do-mato, graxaim & Onívoro \\
\hline \multicolumn{3}{|l|}{ Família Mustelidae } \\
\hline Galictis cuja (Molina, 1782) & Furão-pequeno & Carnívoro \\
\hline \multicolumn{3}{|l|}{ Ordem Xenarthra } \\
\hline \multicolumn{3}{|l|}{ Família Dasypodidae } \\
\hline Dasypus novemcinctus Linnaeus, 1758 & Tatu-galinha & Insetívoro \\
\hline \multicolumn{3}{|l|}{ Ordem Rodentia } \\
\hline \multicolumn{3}{|l|}{ Família Dasyproctidae } \\
\hline Dasyprocta azarae (Lichtenstein, 1823) & Cotia & Herbívoro \\
\hline \multicolumn{3}{|l|}{ Família Cricetidae } \\
\hline Akodon montensis (Thomas, 1913) & & Insetívoro/Onívoro \\
\hline Oligorizomys nigripes (Olfers, 1818) & Rato-catingueiro & $?$ \\
\hline \multicolumn{3}{|l|}{ Família Muridae } \\
\hline Mus musculus Linnaeus, 1758 & Camundongo & Herbívoro \\
\hline Rattus norvegicus (Berkenhout, 1769) & Ratazana & Herbívoro \\
\hline Rattus rattus (Linnaeus, 1758) & Rato, gabiru & Herbívoro \\
\hline \multicolumn{3}{|l|}{ Ordem Didelphimorphia } \\
\hline \multicolumn{3}{|l|}{ Família Didelphidae } \\
\hline Gracilinanus sp. & Cuíca, catita, guaiquica & Frugívoro/Oonívoro \\
\hline Lutreolina crassicaudata (Desmarest, 1804) & Cuíca-de-cauda-grossa, cuíca & Onívoro \\
\hline
\end{tabular}




\begin{tabular}{|c|c|c|}
\hline Taxón & Nome popular & Categoria trófica \\
\hline Didelphis aurita (Wied-Neuwied, 1826) & Gambá, raposa, saruê, seriguê & Onívoro \\
\hline Didelphis albiventris Lund, 1840 & Gambá, raposa, saruê, micurê & Onívoro \\
\hline \multicolumn{3}{|l|}{ Ordem Lagomorpha } \\
\hline \multicolumn{3}{|l|}{ Família Leporidae } \\
\hline Sylvilagus brasiliensis (Linnaeus, 1758) & Coelho, tapiti & Herbívoro \\
\hline Lepus europaeus Pallas, 1778 & Lebre européia, lebrão & Herbívoro \\
\hline \multicolumn{3}{|l|}{ Ordem Chiroptera } \\
\hline \multicolumn{3}{|l|}{ Família Phyllostomidae } \\
\hline Carollia perspicillata (Linnaeus, 1758) & Morcego & Frugívoro \\
\hline Sturnira lilium (E. Geoffroy, 1810) & Morcego & Frugívoro \\
\hline Platyrrhinus lineatus (E. Geoffroy, 1810) & Morcego & Frugívoro \\
\hline Vampyressa pusilla (Wagner,1843) & Morcego & Frugívoro \\
\hline Artibeus lituratus (Olfers, 1813) & Morcego & Frugívoro \\
\hline Pygoderma bilabiatum (Wagner, 1843) & Morcego & Frugívoro \\
\hline Phyllostomus discolor Wagner, 1843 & Morcego & Onívoro \\
\hline \multicolumn{3}{|l|}{ Família Vespertilionidae } \\
\hline Myotis nigricans (Schinz,1821) & Morcego & Insetívoro \\
\hline Eptesicus furinalis (D’Orbigny, 1847) & Morcego & Insetívoro \\
\hline Eptesicus taddeii (Miranda, Bernardi \& Passos, 2006) & Morcego & Insetívoro \\
\hline Família Molossidae & & Insetívoro \\
\hline Cynomops abrasus (Temminck, 1827) & Morcego & Insetívoro \\
\hline Molossus molossus (Pallas, 1766) & Morcego & Insetívoro \\
\hline Nyctinomops laticaudatus (E. Geoffroy, 1805) & Morcego & Insetívoro \\
\hline Tadarida brasiliensis (I. Geoffroy, 1824) & Morcego & Insetívoro \\
\hline Ordem Primates & & Insetívoro \\
\hline \multicolumn{3}{|l|}{ Família Cebidae } \\
\hline Cebus nigritus (Goldfuss, 1809) & Macaco-prego & Onívoro \\
\hline
\end{tabular}

\section{Ornitofauna (178 espécies)}

Em termos de riqueza de espécies, e provavelmente em abundância, as Aves constituíram o grupo de vertebrados dominante, ocorrendo em todos os tipos de hábitats do campus. Com base nos estudos de Gimenes e Anjos (2000) e Lopes e Anjos (2006), e em um registro do gaviãozinho Gampsonyx swainsonii, efetuado por E. V. Lopes em fevereiro de 2006 (um dos primeiros registros da espécie para o Estado), foram identificadas 178 espécies, pertencentes a 46 famílias (Tabela 4).

A família mais abundante foi Tyrannidae, com 29 espécies, $16,4 \%$ do total e 19 a mais que as famílias Columbidae, Trochilidae e Thraupidae, que ficaram empatadas como segundo colocadas em número de espécies. Isto era esperado, visto que esta é a família de aves mais numerosa com ocorrência no Brasil (COMITÊ BRASILEIRO DE REGISTROS ORNITOLÓGICOS, 2006). Por outro lado, famílias de aves também numerosas no Brasil, como Thamnophilidae e Dendrocolaptidae, foram relativamente menos representativas (sete e uma espécies, respectivamente). Isto ocorreu porque essas famílias estão mais associadas ao ambiente florestal, enquanto muitos membros da família Tyrannidae ocupam hábitats em paisagens semi-abertas (SICK, 1997; DEL HOYO; ELLIOTT; SARGATAL, 1992-2005), como ocorreu no campus da UEL, onde de uma forma geral, famílias típicas de hábitats semi-abertos predominaram.

A espécie mais abundante foi a pomba-debando Zenaida auriculata, também conhecida 
como amargozinha ou avoante. A substituição das florestas por áreas de pastagem e de cultivo de grãos favorece espécies que habitam naturalmente áreas abertas, semi-abertas e bordas de florestas (STOTZ et al, 1996). Nas regiões sul e sudeste do Brasil, $Z$. auriculata ocorre em vários hábitats, com exceção dos florestais, inclusive em cidades, e aparentemente explora diferentes tipos de recursos alimentares tais como restos alimentares produzidos pelo homem, e alguns tipos de sementes de interesse econômico (por exemplo: soja, trigo e milho), embora sua preferência seja por sementes de plantas silvestres (RANVAUD et al., 2001). Em vários países da América do Sul, como Colômbia, Argentina e Brasil, a espécie tem sido considerada localmente uma praga para a agricultura (MURTON et al., 1974). Em algumas cidades do Brasil, inclusive Londrina, o grande número de indivíduos (E. V. Lopes, dados não publicados) tem causado preocupações às autoridades em função do potencial de transmissão de patógenos, tendo a espécie como vetor, além da possibilidade de prejuízos para a lavoura e dos incômodos causados pelo acúmulo de dejetos destas aves nos locais de pouso.

Três espécies de aves introduzidas no Brasil, o pombo-doméstico Columba livia, o pardal Passer domesticus e o bico-de-lacre Strilda astrild, foram encontradas. Aparentemente, estão integradas aos ambientes do campus e não representam risco para outras espécies do local, animais ou vegetais, pois nenhuma delas está, ao que parece, em desequilíbrio populacional, ou competindo por recursos de forma muito acirrada com qualquer espécie de ave nativa no campus.

A área do campus abrigou inúmeras espécies de aves que realizam movimentos migratórios em variadas escalas de distância (Tabela 4). A maioria delas não é dependente do ambiente florestal, habitando as bordas deste e locais semi-abertos, bem arborizados, e com disponibilidade de abrigo, locais para nidificação e recursos alimentares. Grande parte dessas espécies passa a primavera e o verão se reproduzindo na região, como por exemplo, algumas espécies da família Tyrannidae, que durante o outono e inverno deslocam-se para regiões mais quentes. Por outro lado, algumas espécies visitam a região durante o outono e o inverno. Parte destes migrantes são aves eminentemente ou preferencialmente frugívoras das famílias Thraupidae e Fringillidae, como sanhaços, saíras e gaturamos. Várias ocorrem na região o ano todo, mas, nesta época se tornam mais abundantes, com a chegada de indivíduos vindos de outras regiões, provavelmente que se tornam muito frias e/ou com pouca disponibilidade de recursos alimentares (SICK, 1997). Aves da família Psittacidae também foram registradas exclusivamente no outono e inverno (LOPES; ANJOS 2006), embora provavelmente não se trate de movimentos migratórios e sim de populações que habitam remanescentes florestais da região, que por algum motivo aumentam sua área de vida nesta época.

Aves frugívoras, especialmente as de grande porte, freqüentemente estão entre as mais ameaçadas pela destruição dos hábitats (WILLIS, 1979; GÖERK, 1997; BIRDLIFE INTERNATIONAL, 2000; PIZO, 2001; RIBON et al., 2003; ANJOS, 2006). Treze espécies (7\%) de aves registradas na UEL são essencialmente frugívoras, sendo que nove delas são de grande porte e uma delas, a jandaia-detesta-vermelha Aratinga auricapillus, é considerada ameaçada de extinção em nível global (COLLAR et al., 1992; BIRDLIFE INTERNATIONAL, 2000). Outras 51 espécies de aves que ocorrem na área são onívoras e podem incluir frutos na dieta. No campus da UEL existe, atualmente, distribuídos de forma esparsa, um número razoável de árvores zoocóricas, algumas exóticas, e outras nativas, além de ervasde-passarinho (e.g. Phoradendron linearifolium Eichler), abundantes na UEL e que parasitam muitas espécies de árvores. Estas fontes de recursos alimentares são fundamentais para a manutenção das populações, não só de aves, como de outros animais que compõe a fauna local.

Comparado ao encontrado em outros campi, o da UEL apresentou uma riqueza de espécies de 
aves relativamente alta. Por exemplo, Höfling e Camargo (1999) registraram 143 espécies para o campus da Universidade de São Paulo, e Monteiro e Brandão (1995), listaram 96 espécies para o campus Samambaia da Universidade Federal de Goiás. Além da importância da disponibilidade de recursos alimentares, discutida acima, outro fator que contribui para explicar a riqueza de aves no campus da UEL é a sua variedade de hábitats (LOPES; ANJOS, 2006), e todos eles, com exceção daqueles constituídos pelas edificações e adjacências, apresentaram espécies de aves exclusivas, ou seja, que na UEL só ocorrem naquele tipo de hábitat. Por exemplo, das 109 espécies de aves registradas no hábitat florestal, 39 (36\%) só ocorrem ali e das 27 registradas no hábitat aquático, 15 (56\%) são exclusivas daquele hábitat (LOPES; ANJOS, 2006). Resumindo, das 174 espécies de aves registradas na UEL, por Lopes e Anjos (2006), 70 foram encontradas em um único tipo de hábitat.

Mesmo representando apenas cerca de 2,6\% da área do campus, o hábitat florestal, representado pelo Horto Florestal, é o mais rico em espécies de aves, e em espécies exclusivas, embora a maior proporção de espécies de aves exclusivas, $56 \%$, pertença ao hábitat aquático. A conservação do hábitat florestal existente no campus é muito importante para a manutenção de sua avifauna. Além do exposto acima, ele é um remanescente da vegetação nativa, que cobria toda a região (MAACK, 1981). Atualmente, existe um estreito corredor florestal (de fato uma capoeira) com 590 m de extensão e trechos de até $15 \mathrm{~m}$ de largura, ligando o horto à vegetação riparia do ribeirão Esperança, o que propicia uma ligação com outros remanescentes florestais na zona rural do município. Vale lembrar que esta é a única face da UEL ainda em contato com a região rural do município, pois as outras três faces já estão cercadas por povoações.

Esta ligação pode contribuir para ampliar o fluxo gênico entre populações, não só de aves, mas da fauna e flora em geral, que habitam o Horto Florestal e as que habitam outros remanescentes da região. Em função da pressão de ocupação humana no entorno da área objeto do presente trabalho, o enriquecimento deste corredor florestal é uma necessidade urgente, com o risco de não poder realizá-lo no futuro, pois as áreas poderão já estar ocupadas com edificações. Tanto este projeto, quanto a difusão de árvores zoocóricas, preferencialmente nativas, no campus, poderiam ser desenvolvidos pela própria instituição, que já possui todo o conhecimento necessário para implementá-los.

No campus da UEL ocorrem manchas de microhábitats que são importantes para ocorrência e permanência de determinadas espécies. Por vezes, não são vistas pelas pessoas como hábitats específicos e por isso não são levadas em conta em decisões conservacionistas, mas em uma escala local tornam-se importantes para a manutenção de algumas populações. Alguns representam sítios específicos para reprodução, como grandes árvores, vivas ou mortas (especialmente as perobas), ali utilizadas por algumas espécies como o pica-pau-de-bandabranca Dryocopus lineatus, o birro Melanerpes candidus e o quiriquiri Falco sparverius. Aves como o urubu-de-cabeça-preta Coragyps atratus e o caracará Caracara plancus também utilizaram freqüentemente árvores de grande porte mortas para ponto de observação e repouso. Outros animais, como morcegos, principalmente os molossídeos e vespertilionídeos, também utilizaram estas árvores mortas como forma de abrigo, quando partes do tronco estavam ocas.

De forma semelhante, algumas espécies como a choca-barrada Thamnophilus doliatus e o petrim Synallaxis frontalis, que habitam preferencialmente o estrato inferior (até $2 \mathrm{~m}$ ) denso, como em capoeira e borda de floresta, são comumente encontradas no campus em locais como cercas-vivas e vegetação arbustiva densa, como as moitas de azaléia Rhododendrum indicum, usadas na jardinagem e os bosques arbustivos que contornam as perobas. Distribuídas por toda a área, estes microhábitats têm sido dizimados, por exemplo, em nome da segurança dos transeuntes, ou mesmo por questões decorativas, 
o que pode acarretar no desaparecimento de algumas espécies de aves.

Outra, e talvez a principal ameaça à avifauna local, é o próprio crescimento do campus, traduzido no número de construções de prédios e estacionamentos. Algumas espécies de aves (pardal, andorinhas, bem-te-vi, corruíra, pombos) e morcegos (molossídeos) utilizam com freqüência construções como forma de abrigo e/ou nidificação, e até utilizam como recurso os restos alimentares dos humanos, dando a impressão de que são beneficiadas com a convivência com o homem. Contudo, isto não deve ser visto como um benefício para a conservação da biodiversidade, pois favorece poucas espécies. Além disso, no caso de uma convivência tão próxima com animais silvestres, sempre existe o potencial de transmissão de zoonozes, tendo estes animais como vetores. No campus esta situação é especialmente potencializada, em instalações que possibilitam que os animais utilizem a forração ou juntas de dilatação.

Cada nova edificação construída na UEL, via de regra, substitui áreas verdes pré-existentes. Estas edificações dificilmente alcançam três pavimentos de altura, ocupando uma área horizontal que poderia ser menor, se os prédios fossem mais altos.
No caso dos estacionamentos, geralmente são pavimentadas grandes extensões. Com isso, sugerese que é necessário estudar medidas que minimizem impactos com a construção de novos edifícios e estacionamentos, a começar pela escolha dos locais para novas construções, de modo que não se reduzam desnecessariamente as áreas verdes, especialmente as com vegetação mais estruturada, e também que não se impermeabilizem o solo em demasia.

Em suma, a conservação da avifauna do campus da UEL, assim como da fauna em geral, está intimamente relacionada com a manutenção de suas áreas verdes. Isto inclui também assegurar a diversidade de hábitats que existe atualmente, como capoeiras, cercas-vivas, floresta, bosques, árvores zoocóricas em áreas semi-abertas e corpos d'água. O remanescente florestal é importantíssimo no contexto da conservação, pois provavelmente está atuando como uma área fonte de espécies e indivíduos que, a partir dele, dispersam e colonizam outros hábitats dentro, ou mesmo fora, via ligação com a vegetação ripária do ribeirão Esperança. Esta ligação pela vegetação ripária também funciona no sentido oposto, ou seja, possibilita a chegada de organismos, primeiramente no Horto Florestal, e que posteriormente podem colonizar outras áreas do campus.

Tabela 4. Nome popular e categoria trófica das espécies de Aves do campus da Universidade Estadual de Londrina, Londrina, PR. *Aves que comprovadamente realizam movimentos migratórios na região, em alguma época do ano.

\begin{tabular}{lll}
\hline Taxón & Nome popular & Categoria trófica \\
\hline $\begin{array}{l}\text { Classe Aves } \\
\text { Ordem Tinamiformes }\end{array}$ & \\
Família Tinamidae & & \\
$\begin{array}{l}\text { Crypturellus parvirostris (Wagler, 1827) } \\
\text { Crypturellus tataupa }(\text { Temminck, 1815) }\end{array}$ & Inhambu-chororó & Onívoro \\
Nothura maculosa $($ Temminck, 1815) & Inhambu-chintã & Onívoro \\
Ordem Anseriformes & Codorna-amarela & Onívoro \\
Família Anatidae & & \\
Subfamília Dendrocygninae & & \\
$\begin{array}{l}\text { Dendrocygna viduata (Linnaeus, 1766) } \\
\text { Subfamília Anatinae }\end{array}$ & Irerê & Onívoro \\
Amazonetta brasiliensis (Gmelin, 1789) & Pé-vermelho & Onívoro
\end{tabular}




\begin{tabular}{|c|c|c|}
\hline Taxón & Nome popular & Categoria \\
\hline \multicolumn{3}{|l|}{ Ordem Pelecaniformes } \\
\hline \multicolumn{3}{|l|}{ Família Phalacrocoracidae } \\
\hline Phalacrocorax brasilianus (Gmelin, 1789) & Biguá & Piscívoro \\
\hline \multicolumn{3}{|l|}{ Ordem Ciconiiformes } \\
\hline \multicolumn{3}{|l|}{ Família Ardeidae } \\
\hline Ardea alba Linnaeus, 1758 & Garça-branca-grande & Piscívoro/c \\
\hline Butorides striata (Linnaeus, 1758) & Socozinho & Piscívoro/C \\
\hline Bubulcus ibis (Linnaeus, 1758) & Garça-vaqueira & Insetívoro \\
\hline \multicolumn{3}{|l|}{ Ordem Cathartiformes } \\
\hline \multicolumn{3}{|l|}{ Família Cathartidae } \\
\hline Coragyps atratus (Bechstein, 1793) & Urubu-de-cabeça-preta & Necrófago \\
\hline \multicolumn{3}{|l|}{ Ordem Falconiformes } \\
\hline \multicolumn{3}{|l|}{ Família Accipitridae } \\
\hline Buteo brachyurus Vieillot, 1816 & Gavião-de-cauda-curta & Carnívoro \\
\hline Elanoides forficatus (Linnaeus, 1758)* & Gavião-tesoura & Insetívoro \\
\hline Elanus leucurus (Vieillot, 1818) & Gavião-peneira & Carnívoro \\
\hline Gampsonyx swainsonii Vigors, 1825 & Gaviãozinho & Carnívoro \\
\hline Rupornis magnirostris (Gmelin, 1788) & Gavião-carijó & Carnívoro \\
\hline \multicolumn{3}{|l|}{ Família Falconidae } \\
\hline Caracara plancus (Miller, 1777) & Caracará & Carnívoro \\
\hline Falco femoralis Temminck, 1822 & Falcão-de-coleira & Carnívoro \\
\hline Falco peregrinus Tunstall, 1771* & Falcão-peregrino & Carnívoro \\
\hline Falco sparverius Linnaeus, 1758 & Quiriquiri & Carnívoro \\
\hline Milvago chimachima (Vieillot, 1816) & Carrapateiro & Carnívoro \\
\hline \multicolumn{3}{|l|}{ Ordem Gruiformes } \\
\hline \multicolumn{3}{|l|}{ Família Rallidae } \\
\hline Aramides cajanea (Statius Muller, 1776) & Saracura-três-potes & Onívoro \\
\hline Aramides saracura (Spix, 1825) & Saracura-do-mato & Onívoro \\
\hline Gallinula chloropus (Linnaeus, 1758) & Frango-d'água-comum & Onívoro \\
\hline Laterallus melanophaius (Vieillot, 1819) & Sanã-parda & Onívoro \\
\hline \multicolumn{3}{|l|}{ Ordem Charadriiformes } \\
\hline \multicolumn{3}{|l|}{ Família Charadriidae } \\
\hline Vanellus chilensis (Molina, 1782) & Quero-quero & Insetívoro \\
\hline \multicolumn{3}{|l|}{ Família Scolopacidae } \\
\hline Tringa solitaria Wilson, $1813^{*}$ & Maçarico-solitário & Insetívoro \\
\hline \multicolumn{3}{|l|}{ Família Jacanidae } \\
\hline Jacana jacana (Linnaeus, 1766) & Jaçanã & Insetívoro \\
\hline \multicolumn{3}{|l|}{ Ordem Columbiformes } \\
\hline \multicolumn{3}{|l|}{ Família Columbidae } \\
\hline Columba livia Gmelin, 1789 & Pombo-doméstico & Granívoro \\
\hline Columbina picui (Temminck, 1813) & Rolinha-picui & Granívoro \\
\hline Columbina squammata (Lesson, 1831) & Fogo-apagou & Granívoro \\
\hline Columbina talpacoti (Temminck, 1811) & Rolinha-roxa & Granívoro \\
\hline Geotrygon montana (Linnaeus, 1758) & Pariri & Onívoro \\
\hline Leptotila verreauxi Bonaparte, 1855 & Juriti-pupu & Onívoro \\
\hline Leptotila rufaxilla (Richard \& Bernard, 1792) & Juriti-gemedeira & Onívoro \\
\hline Patagioenas cayennensis (Bonnaterre, 1792) & Pomba-galega & Frugívoro \\
\hline Patagioenas picazuro (Temminck, 1813) & Pombão & Granívoro \\
\hline Zenaida auriculata (Des Murs, 1847) & Pomba-de-bando & Granívoro \\
\hline
\end{tabular}




\begin{tabular}{ll}
\hline Taxón & Nome popular \\
\hline Ordem Psittaciformes & \\
Família Psittacidae & \\
Amazona aestiva (Linnaeus, 1758) & Papagaio-verdadeiro \\
Aratinga auricapillus (Kuhl, 1820) & Jandaia-de-testa-vermelha \\
Aratinga leucophthalma (Statius Muller, 1776) & Periquitão-maracanã \\
Forpus xanthopterygius (Spix, 1824) & Tuim \\
Pionopsitta pileata (Scopoli, 1769) & Cuiú-cuiú \\
Pionus maximiliani (Kuhl, 1820) & Maitaca-verde \\
Pyrrhura frontalis (Vieillot, 1817) & Tiriba-de-testa-vermelha
\end{tabular}

Categoria trófica

\section{Ordem Cuculiformes}

\section{Família Cuculidae}

\section{Subfamília Cuculinae}

Coccyzus melacoryphus Vieillot, 1817*

Piaya cayana (Linnaeus, 1766)

Subfamília Crotophaginae

Crotophaga ani Linnaeus, 1758

Guira guira (Gmelin, 1788)

\section{Subfamília Neomorphinae}

Tapera naevia (Linnaeus, 1766)

Ordem Strigiformes

Família Strigidae

Athene cunicularia (Molina, 1782)

Megascops choliba (Vieillot, 1817)

Ordem Caprimulgiformes

\section{Família Nyctibiidae}

Nyctibius griseus (Gmelin, 1789)

Família Caprimulgidae

Chordeiles minor (Forster, 1771)

Lurocalis semitorquatus (Gmelin, 1789)

Nyctidromus albicollis (Gmelin, 1789)

\section{Ordem Apodiformes}

\section{Família Apodidae}

Chaetura meridionalis Hellmayr, 1907

Família Trochilidae

\section{Subfamília Phaethornithinae}

Phaethornis eurynome (Lesson, 1832)

Phaethornis pretrei (Lesson \& Delattre, 1839)

\section{Subfamília Trochilinae}

Amazilia lactea (Lesson, 1832)

Amazilia versicolor (Vieillot, 1818)

Anthracothorax nigricollis (Vieillot, 1817)

Chlorostilbon lucidus (Shaw, 1812)

Eupetomena macroura (Gmelin, 1788)

Florisuga fusca (Vieillot, 1817)

Heliomaster squamosus (Temminck, 1823)

Hylocharis chrysura (Shaw, 1812)

Leucochloris albicollis (Vieillot, 1818)

Thalurania glaucopis (Gmelin, 1788)

Papa-lagarta-acanelado

Alma-de-gato

Anu-preto

Anu-branco

Saci

Coruja-buraqueira

Corujinha-do-mato

Mãe-da-lua

Bacurau-norte-americano

Tuju

Bacurau

Andorinhão-do-temporal

Rabo-branco-de-garganta-rajada

Rabo-branco-acanelado

Beija-flor-de-peito-azul

Beija-flor-de-banda-branca

Beija-flor-de-veste-preta

Besourinho-de-bico-vemelho

Beija-flor-tesoura

Beija-flor-preto

Bico-reto-de-banda-branca

Beija-flor-dourado

Beija-flor-de-papo-branco

Beija-flor-de-fronte-violeta
Frugívoro

Frugívoro

Frugívoro

Frugívoro

Frugívoro

Frugívoro

Frugívoro

Insetívoro

Insetívoro

Insetívoro

Insetívoro

Insetívoro

Carnívoro/Insetívoro

Carnívoro

Insetívoro

Insetívoro

Insetívoro

Insetívoro

Insetívoro

Nectarívoro

Nectarívoro

Nectarívoro

Nectarívoro

Nectarívoro

Nectarívoro

Nectarívoro

Nectarívoro

Nectarívoro

Nectarívoro

Nectarívoro

Nectarívoro 


\begin{tabular}{l}
\hline Taxón \\
\hline Ordem Coraciiformes \\
Família Alcedinidae \\
Ceryle torquatus (Linnaeus, 1766) \\
Chloroceryle amazona (Latham, 1790) \\
Chloroceryle americana (Gmelin, 1788) \\
Família Bucconidae
\end{tabular}

Nome popular

Categoria trófica

Nonnula rubecula (Spix, 1824)

Martim-pescador-grande

Martim-pescador-verde

Martim-pescador-pequeno

Macuru

Araçari-poca

Pica-pau-de-cabeça-amarela

Pica-pau-do-campo

Pica-pau-verde-barrado

Pica-pau-de-banda-branca

Birro, pica-pau-branco

Benedito-de-testa-amarela

Pica-pau-anão-de-coleira

Picapauzinho-verde-carijó

Choquinha-lisa

Chocão-carijó

Borralhara

Papa-taoca-do-sul

Choca-da-mata

Choca-barrada

Choca-de-chapéu-vermelho

Chupa-dente

Arapaçu-grande

João-de-barro

Petrim

Pichororé

João-teneném

Bico-virado-carijó

Estalador

Cabeçudo

Tororó

Ferreirinho-relógio

Risadinha

Marianinha-amarela

Guaracava-de-barriga-amarela
Piscívoro

Piscívoro

Piscívoro

Insetívoro

Frugívoro

Insetívoro

Insetívoro

Insetívoro

Insetívoro

Insetívoro

Insetívoro

Insetívoro

Insetívoro

Insetívoro

Insetívoro

Insetívoro

Insetívoro

Insetívoro

Insetívoro

Insetívoro

Insetívoro

Insetívoro

Insetívoro

Insetívoro

Insetívoro

Insetívoro

Insetívoro

Insetívoro

Insetívoro

Insetívoro

Insetívoro

Insetívoro

Insetívoro

Onívoro 


\begin{tabular}{|c|c|c|}
\hline Taxón & Nome popular & Categoria trófica \\
\hline Elaenia parvirostris Pelzeln, $1868^{*}$ & Guaracava-de-bico-curto & Onívoro \\
\hline Myiornis auricularis (Vieillot, 1818) & Miudinho & Insetívoro \\
\hline Phylloscartes ventralis (Temminck, 1824) & Borboletinha-do-mato & Insetívoro \\
\hline Serpophaga subcristata (Vieillot, 1817) & Alegrinho & Insetívoro \\
\hline Tolmomyias sulphurescens (Spix, 1825)* & Bico-chato-de-orelha-preta & Insetívoro \\
\hline \multicolumn{3}{|l|}{ Subfamília Fluvicolinae } \\
\hline Colonia colonus (Vieillot, 1818)* & Viuvinha & Insetívoro \\
\hline Lathrotriccus euleri (Cabanis, 1868) & Enferrujado & Insetívoro \\
\hline Machetornis rixosa (Vieillot, 1819) & Suiriri-cavaleiro & Insetívoro \\
\hline Myiophobus fasciatus (Statius Muller, 1776) & Filipe & Insetívoro \\
\hline Pyrocephalus rubinus (Boddaert, 1783)* & Príncipe & Insetívoro \\
\hline Satrapa icterophrys (Vieillot, 1818)* & Suiriri-pequeno & Insetívoro \\
\hline \multicolumn{3}{|l|}{ Subfamília Tyranninae } \\
\hline Empidonomus varius (Vieillot, 1818)* & Peitica & Onívoro \\
\hline $\begin{array}{l}\text { Griseotyrannus aurantioatrocristatus (d'Orbigny \& } \\
\text { Lafresnaye, 1837)* }\end{array}$ & Peitica-de-chapéu-preto & Onívoro \\
\hline Legatus leucophaius (Vieillot, 1818)* & Bem-te-vi-pirata & Onívoro \\
\hline Megarynchus pitangua (Linnaeus, 1766)* & Neinei & Onívoro \\
\hline Myiarchus swainsoni Cabanis \& Heine, $1859^{*}$ & Irré & Onívoro \\
\hline Myiodynastes maculatus (Statius Muller, 1776)* & Bem-te-vi-rajado & Onívoro \\
\hline Myiozetetes similis (Spix, 1825)* & $\begin{array}{l}\text { Bentevizinho-de-Penacho- } \\
\text { vermelho }\end{array}$ & Onívoro \\
\hline Pitangus sulphuratus (Linnaeus, 1766) & Bem-te-vi & Onívoro \\
\hline Sirystes sibilator (Vieillot, 1818)* & Gritador & Onívoro \\
\hline Tyrannus melancholicus Vieillot, 1819* & Suiriri & Onívoro \\
\hline Tyrannus savana Vieillot, $1808^{*}$ & Tesourinha & Onívoro \\
\hline \multicolumn{3}{|l|}{ Família Tityridae } \\
\hline Pachyramphus polychopterus (Vieillot, 1818)* & Caneleiro-preto & Onívoro \\
\hline Pachyramphus validus (Lichtenstein, 1823)* & Caneleiro-de-chapéu-preto & Onívoro \\
\hline Tityra cayana (Linnaeus, 1766) & Anambé-branco-de-Rabo-preto & Frugívoro \\
\hline Tityra inquisitor (Lichtenstein, 1823) & $\begin{array}{l}\text { Anambé-branco-de-Bochecha- } \\
\text { parda }\end{array}$ & Frugívoro \\
\hline \multicolumn{3}{|l|}{ Família Vireonidae } \\
\hline Cyclarhis gujanensis (Gmelin, 1789) & Pitiguari & Insetívoro \\
\hline Vireo olivaceus (Linnaeus, 1766)* & Juruviara & Insetívoro \\
\hline \multicolumn{3}{|l|}{ Família Corvidae } \\
\hline Cyanocorax chrysops (Vieillot, 1818) & Gralha-picaça & Onívoro \\
\hline \multicolumn{3}{|l|}{ Família Hirundinidae } \\
\hline Hirundo rustica Linnaeus, 1758* & Andorinha-de-bando & Insetívoro \\
\hline Progne chalybea (Gmelin, 1789)* & Andorinha-doméstica-grande & Insetívoro \\
\hline Progne tapera (Vieillot, 1817)* & Andorinha-do-campo & Insetívoro \\
\hline Pygochelidon cyanoleuca (Vieillot, 1817) & Andorinha-pequena-de-casa & Insetívoro \\
\hline Stelgidopteryx ruficollis (Vieillot, 1817) & Andorinha-serradora & Insetívoro \\
\hline Tachycineta leucorrhoa (Vieillot, 1817)* & Andorinha-de-sobre-branco & Insetívoro \\
\hline \multicolumn{3}{|l|}{ Família Troglodytidae } \\
\hline Troglodytes musculus Naumann, 1823 & Corruíra & Insetívoro \\
\hline \multicolumn{3}{|l|}{ Família Donacobiidae } \\
\hline Donacobius atricapilla (Linnaeus, 1766) & Japacanim & Insetívoro \\
\hline \multicolumn{3}{|l|}{ Família Turdidae } \\
\hline Turdus albicollis Vieillot, 1818* & Sabiá-coleira & Onívoro \\
\hline
\end{tabular}




\begin{tabular}{|c|c|c|}
\hline Taxón & Nome popular & Categoria trófica \\
\hline Turdus amaurochalinus Cabanis, $1850^{*}$ & Sabiá-poca & Onívoro \\
\hline Turdus leucomelas Vieillot, 1818 & Sabiá-barranco & Onívoro \\
\hline Turdus rufiventris Vieillot, 1818 & Sabiá-laranjeira & Onívoro \\
\hline \multicolumn{3}{|l|}{ Família Mimidae } \\
\hline Mimus saturninus (Lichtenstein, 1823) & Sabiá-do-campo & Onívoro \\
\hline \multicolumn{3}{|l|}{ Família Motacillidae } \\
\hline Anthus lutescens Pucheran, 1855 & Caminheiro-zumbidor & Onívoro \\
\hline \multicolumn{3}{|l|}{ Família Coerebidae } \\
\hline Coereba flaveola (Linnaeus, 1758) & Cambacica & Nectarívoro \\
\hline \multicolumn{3}{|l|}{ Família Thraupidae } \\
\hline Cissopis leverianus (Gmelin, 1788) & Tietinga & Onívoro \\
\hline Conirostrum speciosum (Temminck, 1824) & Figuinha-de-rabo-castanho & Onívoro \\
\hline Dacnis cayana (Linnaeus, 1766) & Saí-azul & Onívoro \\
\hline Hemithraupis guira (Linnaeus, 1766) & Saíra-de-papo-preto & Onívoro \\
\hline Nemosia pileata (Boddaert, 1783)* & Saíra-de-chapéu-preto & Onívoro \\
\hline Pipraeidea melanonota (Vieillot, 1819) & Saíra-viúva & Onívoro \\
\hline Tachyphonus coronatus (Vieillot, 1822) & Tiê-preto & Onívoro \\
\hline Tersina viridis (Illiger, 1811)* & Saí-andorinha & Onívoro \\
\hline Thraupis sayaca (Linnaeus, 1766)* & Sanhaçu-cinzento & Onívoro \\
\hline Trichothraupis melanops (Vieillot, 1818) & Tiê-de-topete & Onívoro \\
\hline \multicolumn{3}{|l|}{ Família Emberizidae } \\
\hline Ammodramus humeralis (Bosc, 1792) & Tico-tico-do-campo & Granívoro \\
\hline Arremon flavirostris Swainson, 1838 & Tico-tico-de-bico-amarelo & Onívoro \\
\hline Coryphospingus cucullatus (Statius Muller, 1776) & Tico-tico-rei & Onívoro \\
\hline Sporophila caerulescens (Vieillot, 1823) & Coleirinho & Granívoro \\
\hline Sporophila lineola (Linnaeus, 1758) & Bigodinho & Granívoro \\
\hline Volatinia jacarina (Linnaeus, 1766) & Tiziu & Granívoro \\
\hline Zonotrichia capensis (Statius Muller, 1776) & Tico-tico & Granívoro \\
\hline \multicolumn{3}{|l|}{ Família Cardinalidae } \\
\hline Cyanocompsa brissonii (Lichtenstein, 1823) & Azulão & Onívoro \\
\hline Saltator similis d'Orbigny \& Lafresnaye, 1837 & Trinca-ferro-verdadeiro & Onívoro \\
\hline \multicolumn{3}{|l|}{ Família Parulidae } \\
\hline Basileuterus culicivorus (Deppe, 1830) & Pula-pula & Insetívoro \\
\hline Basileuterus leucoblepharus (Vieillot, 1817) & Pula-pula-assobiador & Insetívoro \\
\hline Geothlypis aequinoctialis (Gmelin, 1789) & Pia-cobra & Insetívoro \\
\hline Parula pitiayumi (Vieillot, 1817) & Mariquita & Insetívoro \\
\hline \multicolumn{3}{|l|}{ Família Icteridae } \\
\hline Cacicus haemorrhous (Linnaeus, 1766) & Guaxe & Onívoro \\
\hline Gnorimopsar chopi (Vieillot, 1819) & Graúna & Onívoro \\
\hline Molothrus bonariensis (Gmelin, 1789) & Vira-bosta & Onívoro \\
\hline Sturnella superciliaris (Bonaparte, 1850) & Polícia-inglesa-do-sul & Onívoro \\
\hline \multicolumn{3}{|l|}{ Família Fringillidae } \\
\hline Carduelis magellanica (Vieillot, 1805) & Pintassilgo & Granívoro \\
\hline Euphonia chlorotica (Linnaeus, 1766)* & Fim-fim & Frugívoro \\
\hline Euphonia cyanocephala (Vieillot, 1818)* & Gaturamo-rei & Frugívoro \\
\hline \multicolumn{3}{|l|}{ Família Estrildidae } \\
\hline Estrilda astrild (Linnaeus, 1758) & Bico-de-lacre & Granívoro \\
\hline \multicolumn{3}{|l|}{ Família Passeridae } \\
\hline Passer domesticus (Linnaeus, 1758) & Pardal & Onívoro \\
\hline
\end{tabular}


O campus da UEL ainda apresenta uma fauna rica, distribuída nos mais diferentes ambientes, onde podem ser encontrados materiais para pesquisas e atividades didáticas. Além disso, visitantes podem utilizá-lo como área de lazer e de aprendizagem, com possibilidades de observar quantidades apreciáveis de espécies de animais. Assim, muitas áreas merecem ser preservadas ou restauradas, visando à manutenção, ou até mesmo o enriquecimento natural de sua fauna. Estudos sobre a flora e a fauna de invertebrados ainda são necessários para melhor conhecer a biodiversidade do campus, tornando mais refinadas as propostas de preservação de seus ambientes.

\section{Agradecimentos}

Somos especialmente gratos a Nélio Roberto dos Reis, Vlamir J. Rocha, Gisele Aparecida da Silva Doratti dos Santos pelas informações relativas aos mamíferos. Ao Fausto Carmelo de Lima, diretor de Planejamento e desenvolvimento físico, Pró-reitoria de Planejamento da UEL e sua equipe, pelas informações relativas ao campus da UEL. A Ana Odete Santos Vieira pela correção dos nomes científicos das plantas. OAS é bolsista de Produtividade em Pesquisa do CNPq.

\section{Referências}

AB'SABER, A. N. Os domínios morfoclimáticos na América do Sul: primeira aproximação. Geomorfologia, São Paulo, v. 52, n. 1, p. 1-21, 1977.

AGOSTINHO, A. A.; HAHN, N. S.; GOMES, L. C.; BINI, L. M. Estrutura Trófica. In: VAZZOLER, A. E. A. M.; AGOSTINHO, A. A.; HAHN, N. S. (Org.). A planície de inundação do alto rio Paraná: aspectos físicos, biológicos e socioeconômicos. Maringá: EDUEM, 1997. p. 229-248.

ANJOS, L. Bird species sensitivity in a fragmented landscape of the Atlantic forest in southern Brazil. Biotropica, Oxford, v. 38, n. 2, p. 229-234, 2006.
ARAÚJO, F. G. Adaptação do índice de integridade biótica usando a comunidade de peixes para o rio Paraíba do Sul. Revista Brasileira de Biologia, São Carlos, v. 58, n. 4, p. 547-558, 1998.

BALDISSERA JÚNIOR, F. A.; CARAMASCHI, U.; HADDAD, C. F. B. Review of the Bufo crucifer species group, with description of two new related species (Amphibia, Anura, Bufonidae). Arquivos do Museu Nacional, Rio de Janeiro, v. 62, n. 3, p. 255-282, 2004.

BENNEMANN, S. T.; SHIBATTA, O.A.; GARAVELLO, J. C. Peixes da bacia do rio Tibagi: uma abordagem ecológica. Londrina: EDUEL, 2000.

BERNARDE, P. S.; MACHADO, R. A. Fauna reptiliana da Bacia do Rio Tibagi. In: MEDRI, M. E.; BIANCHINI, E.; SHIBATTA, O. A.; PIMENTA, J. A. (Org.). A bacia do rio Tibagi. Londrina: M. E. Medri, 2003. p. 291-296.

BIRDLIFE INTERNATIONAL. Threatened birds of the world. Barcelona: Lynx Edition, BirdLife International \& Cambridge, 2000.

BREDT, A.; ARAÚJO, F. A. A.; CAETANO-JÚNIOR, J.; RODRIGUES, M. G. R.; YOSHIZAWA, M.; SILVA, M. M. S.; HARMANI, N. M. S.; MASSUNAGA, P. N. T.; BÜRER, S. P.; POTRO, V. A. R.; UIEDA, W. Morcegos em áreas urbanas e rurais: manual de manejo e controle. Brasília: Fundação Nacional de Saúde \& Ministério da Saúde, 1996.

CÁCERES, N. C.; GHIZONI JÚNIOR, I. R.; GRAIPEL, M. E. Diet of two marsupials, Lutreolina crassicaudata and Micoureus demerarae, in a coastal Atlantic Forest island of Brazil. Mammalia, Berlin, v. 66, n. 3, p. 331340, 2002.

CASATTI, L. Alimentação dos peixes em um riacho do PARQUE ESTADUAL MORRO DO DIABO, bacia do alto rio Paraná, sudeste do Brasil. Biota Neotropica, Campinas, v. 2, n. 2, p. 1-14. 2002.

CASATTI, L.; LANGEANI, F; CASTRO, R. M. C. Peixes de riacho do parque estadual Morro do Diabo, bacia do alto rio Paraná. Biota Neotropica, Campinas, v. 1, n. 1, p. 1-15. 2001.

CASTRO, E. R.; GALETTI, M. Frugivoria e dispersão de sementes pelo lagarto teiú Tupinambis merianae (Reptilia, Teiidae). Papéis Avulsos de Zoologia, São Paulo, v. 44, n. 6, p. 91-97, 2004.

CHEIDA, C. C.; NAKANO-OLIVEIRA, E.; FUSCOCOSTA, R.; ROCHA-MENDES, F.; QUADROS, J. Ordem Carnívora In: REIS, N. R.; PERACCHI, A. L. PEDRO, W. A.; LIMA, I. P. (Ed.). Mamíferos do Brasil. Londrina: N. R. Reis, 2006. p. 231-275. 
COLLAR, N. J.; GONZAGA, L. P.; KRABBE, N.; MADROÑO NIETO, A.; NARANJO, L. G.; PARKER III, T. A; WEGE, D. C. Threatened birds of the Americas: the ICBP/IUCN red data book. Washington: Smithsonian Institution Press, 1992.

COLLI, G. R., PERES JÚNIOR, A. K.; CUNHA, H. J. A new species of Tupinambis. Herpetologica, Lafayette, v. 54, n. 4, p. 477-492, 1998.

COMITÊ BRASILEIRO DE REGISTROS ORNITOLÓGICOS. Listas das aves do Brasil. Versão 15/7/2006. 2006. Disponível em: <http://www.cbro.org. br>. Acesso em: 24 jul. 2007.

COMPANHIA ENERGÉTICA DE MINAS GERAIS - CEMIG; CENTRO TECNOLÓGICO DE MINAS GERAIS - CETEC. Guia ilustrado de peixes da bacia do rio Grande. Belo Horizonte: CEMIG/CETEC, 2000.

DEL HOYO, J.; ELLIOTT, A.; SARGATAL, J. Handbook of the birds of the world. Barcelona: Linx Edicions, 19922005. v. 1-10.

DUELLMAN, W. E.; TRUEB, L. Biology of amphibians. Baltimore: McGraw-Hill, 1986.

DUKE ENERGY. Peixes do rio Paranapanema. São Paulo: Horizonte Geográfico, 2003.

FAIVOVICH, J.; HADDAD, C. F. B.; GARCIA, P. C. A.; FROST, D. R.; CAMPBELL, J. A.; WHEELER, W. C. Systematic review of the frog family Hylidae, with special reference to the Hylinae: phylogenetic analysis and taxonomic revision. Bulletin American Museum of Natural History, New York, n. 294, p. 1-240, 2005.

FROST, D. R. Amphibians species of the world 3.0 - an online reference. American Museum of Natural History, New York. 2004. Disponível em: <http://research.amnh. org/herpetology/amphibia/index.php>. Acesso em: 27 jun. 2007.

FROST, D. R.; GRANT, T.; FAIVOVICH, J.; HADDAD, C. F. B.; BAIN, R. H.; HAAS, A.; DE-SÁ, R. O.; CHANNING, A.; WILKINSON, M.; WHEELER, W. C. The amphibian tree of life. Bulletin of the American Museum of Natural History, New York, n. 297, p. 1-370, 2006.

GIMENES, M, R; ANJOS, L. Distribuição espacial de aves em um fragmento florestal do campus da Universidade Estadual de Londrina, norte do Paraná, Brasil. Revista Brasileira de Zoologia, Curitiba, v. 17, n. 1, p. 263-271, 2000.

GOELDI, E. Lagartos do Brazil. Boletim do Museu Paraense, Belém do Pará, v. 3, n. 3/4, p. 370-399, 1902.
GÖERCK, J. M., Patterns of rarity in birds of the Atlantic forest of Brazil. Conservation Biology, Oxford, v. 11, n. 1, p. 112-118, 1997.

GRAÇA, W. J.; PAVANELLI, C. S. Peixes da planície de inundação do alto rio Paraná e áreas adjacentes. Maringá: EDUEM, 2007.

HADDAD, C. F. B.; PRADO, C. P. A. Reproductive modes in frogs and their unexpected diversity in the Atlantic forest of Brazil. BioScience, Washington, v. 55, n. 3, p. 207-217, 2005.

HAHN, N. S.; FUGI, R.; ANDRIAN, I. F. Trophic ecology of the fish assemblages. In: THOMAZ, S. M; AGOSTINHO, A. A.; HAHN, N. S. (Org.). The upper Paraná river and its floodplain: physical aspects, ecology and conservation. Leiden: Backhuys Publishers, 2004. p. 247-269.

HÖFLING, E.; CAMARGO, H. F. A. Aves no campus. $3^{\text {a. }}$ ed. São Paulo: EDUSP, 1999.

PARANAENSE

$\mathrm{DE}$ DESENVOLVIMENTO ECONÔMICO E SOCIAL IPARDES. Cobertura florestal e consumo de madeira, lenha e carvão nas micro regiões de Londrina, Maringá e Paranavaí: subsidio para uma política florestal no estado do Paraná. Curitiba: IPARDES, 1993.

LEWINSON, T. M.; PRADO, P. I. (Ed.). Biodiversidade brasileira: síntese do estado atual do conhecimento. São Paulo: Contexto, 2002.

LIMA, I. P. Aspectos ecológicos dos quirópteros do "Campus" da Universidade Estadual de Londrina - PR. 1994. Trabalho de Conclusão de Curso. (Bacharelado em Ciências Biológicas) - Universidade Estadual de Londrina, Londrina.

LOPES, E, V.; ANJOS, L. A composição da avifauna do campus da Universidade Estadual de Londrina, norte do Paraná, Brasil. Revista Brasileira de Zoologia, Curitiba, v. 23, n. 1, p. 145-156, 2006.

LUZ-AGOSTINHO, K. D. G.; BINI, L. M. FUGI, R.; AGOSTINHO, A. A.; JULIO JUNIOR, H. F. Food spectrum and trophic structure of the ichthyofauna of Corumbá reservoir, Paraná river basin, Brazil. Neotropical Ichthyology, Porto Alegre, v. 4, n. 1, p. 61-68, 2006.

MAACK, R. Geografia física do estado do Paraná. Rio de Janeiro: Livraria José Olympio, 1981.

MACHADO, R. A. Herpetofauna do campus universitário da Universidade Estadual de Londrina, Município de Londrina, Paraná. (Amphibia e Reptilia). 1996. Trabalho de Conclusão de Curso. (Bacharelado em Ciências Biológicas) - Universidade Estadual de Londrina, Londrina. 
MACHADO, R. A.; BERNARDE, P. S.; MORATO, S. A. A.; ANJOS, L. Análise comparada da riqueza de anuros entre duas áreas com diferentes estados de conservação no Município de Londrina, Paraná, Brasil (Amphibia: Anura). Revista Brasileira de Zoologia, Curitiba, v. 16, n. 4, p. 997-1004, 1999.

MACHADO, R. A.; BERNARDE, P.S. Anurofauna da Bacia do Rio Tibagi. In: MEDRI, M. E.; BIANCHINI, E.; SHIBATTA, O. A.; PIMENTA, J. A. (Org.). A bacia do Rio Tibagi. Londrina: M. E. Medri, 2003. p. 297-306.

MARGARIDO, T. C. M.; BRAGA, F. G. Mamíferos. In: MIKICH, S. B.; BÉRNILS, R. S.(Ed.). Livro vermelho da fauna ameaçada no estado do Paraná. Curitiba: Instituto Ambiental do Paraná, 2004. p. 25-142.

MONTEIRO, M. P.; BRANDÃO, D. Estrutura da comunidade de aves do "Campus Samambaia" da Universidade Federal de Goiás, Goiânia, Brasil. Ararajuba, Rio de Janeiro, v. 3, n. 1, p. 21-26, 1995.

MONTEIRO-FILHO, E. L. A.; DIAS, V. S. Observações sobre a biologia de Lutreolina crassicaudata (Mammalia: Marsupialia). Revista Brasileira de Biologia, São Paulo, v. 50, n. 2, p. 393-399, 1990.

MULLER, M. F; REIS, N. R. Partição de recursos alimentares entre quatro espécies de morcegos frugívoros (Chiroptera, Phyllostomidae). Revista Brasileira de Zoologia, Curitiba, v. 9, n. 3/4, p. 345-355, 1992.

MURTON, R. K.; BUCHER, E. H.; NORES, M.; GOMES, E.; REARTES, J. The ecology of the Eared Dove (Zenaida auriculata) in Argentina. The Condor, Lawrance, v. 76, n. 1, p. 80-88, 1974.

NELSON, J. S. Fishes of the world. New Jersey: John Wiley \& Sons, 2006.

OLIVEIRA, D. C.; BENNEMANN, S. T. Ictiofauna, recursos alimentares e relações com as interferências antrópicas em um riacho urbano no Sul do Brasil. Biota Neotropica, Campinas, v. 5, n. 1, p. 1-13, 2005.

PEDRO, W. A. Morcegos na área urbana. Biológico, São Paulo, v. 60, n. 2, p. 101-102, 1998.

PEDRO, W. A.; PASSOS, F. C. Diversidade de morcegos no Brasil. In: SEMINÁRIO INTERNACIONAL: MORCEGOS COMO TRANSMISSORES DA RAIVA, 1., 2001, São Paulo. Resumos... São Paulo: Instituto Pasteur, Fundação Nacional de Saúde, Ministério da Saúde, 2001. p. 17-19.

PIZO, M. A. A conservação das aves frugívoras. In: ALBUQUERQUE, J. L., J. F. CÂNDIDO-JUNIOR, F. C. STRAUBE; A. ROOS (Ed.). Ornitologia e conservação: da ciência às estratégias. Tubarão: Editora da Unisul, 2001. p. 49-59.
RANVAUD, R.; FREITAS, K. C.; BUCHER, E. H.; DIAS, H. S; AVANJO, V. C.; ALBERTS, C. C. Diet of Eared Doves (Zenaida auriculata, Aves, Columbidae) in a sugar-cane colony in South-eastern Brazil. Brazilian Journal of Biology, São Carlos, v. 61, n. 4, p. 651-660, 2001.

REIS, N. R.; BARBIERI, M. S.; LIMA, I. P.; PERACCHI, A. L. O que é melhor para manter a riqueza de espécies de morcegos (Mammalia, Chiroptera): um fragmento florestal grande ou vários fragmentos de pequeno tamanho? Revista Brasileira de Zoologia, Curitiba, v. 20, n. 2, p. 225-230, 2003.

REIS, N. R.; LIMA I. P.; PERACCHI A. L. Morcegos (Chiroptera) da área Urbana de Londrina, Paraná, Brasil. Revista Brasileira de Zoologia, Curitiba, v. 19, n. 3, p. 739-746, 2002.

RIBON, R., J. E. SIMON; G. T. MATTOS. Bird extinctions in Atlantic forest fragments of the Viçosa region, southeastern Brazil. Conservation Biology, Oxford, v. 17, p. 1827-1839, 2003.

ROCHA, V. J. Desenvolvimento de um método de manejo envolvendo um grupo de macacos-pregos (Cebus apella) em condição semi-selvagem no horto florestal da UEL, Londrina - PR. 1992. Trabalho de Conclusão de Curso. (Bacharelado em Ciências Biológicas) - Universidade Estadual de Londrina, Londrina.

ROSSI, R. V.; BIANCONI, G. V.; PEDRO W. A. Ordem didelphymorphia. In: REIS, N. R.; PERACCHI, A. L. PEDRO, W. A.; LIMA, I. P. (Ed.). Mamíferos do Brasil. Londrina: N. R. Reis, 2006. p. 27-66.

RYDELL, J. Exploitation of insects around streetlamps by bats in Sweden. Functional Ecology, Londres, v. 6, n. 6, p. 744-750, 1992.

SANTORI, R. T.; ROCHA-BARBOSA, O.; VIEIRA, M. V.; MAGNAN-NETO, J. A.; LOGUERCIO, M. F. C. Locomotion in aquatic, terrestrial, and arboreal hábitat of thick-tailed opossum, Lutreolina crassicaudata (Desmarest, 1804). Journal of Mammalogy, Lawrence, v. 86, n. 5, p. 902-908, 2005.

SHIBATTA, O. A., ORSI, M. L., BENNEMANN, S. T.; SILVA-SOUZA, Â. T. Diversidade e distribuição de peixes na bacia do rio Tibagi. In: MEDRI, M.E., BIANCHINI, E., SHIBATTA, O. A.; PIMENTA, J. A. A bacia do rio Tibagi. Londrina: M. E. Medri, 2002. p. 403-423.

SICK, H. Ornitologia brasileira. Rio de Janeiro: Nova Fronteira, 1997.

SILVEIRA, G. Análise das três dimensões básicas do nicho (alimento, espaço e tempo) de Cebus apella nigritus 
(Goldfuss, 1809) (Primates, Cebidae) em um fragmento florestal de Londrina, Paraná. 2003. Dissertação. (Mestrado em Ciências Biológicas) - Universidade Estadual de Londrina, Londrina.

SOCIEDADE BRASILEIRA DE HERPETOLOGIA - SBH. Lista de espécies de répteis do Brasil. 2005. Disponível em: <http://www2.sbherpetologia.org.br/ checklist/repteis.htm>. Acesso em: 27 jun. 2007.

STOTZ, D. F.; FITZPATRICK, J. W.; PARKER III, T. A.; MOSKOVITS, D. K. Neotropical birds: ecology and conservation. Chicago: University of Chicago Press, 1996.

UETZ, P. The new reptile database. Research Center Karlsruhe, Karlsruhe, 2007. Disponível em: <http:// www.reptile-database.org>. Acesso em: 21 ago. 2007.

UIEDA, W. Morcegos, ecologia e saúde pública. 1999. Disponível em: <http://proex.reitoria.unesp. br/congressos/Congressos/1__Congresso/Sa_de_e_ Qualidade_de_Vida/Trabalho1 $\overline{6} \cdot \bar{h}$ tm $>$. Acesso em: maio 2007.
VIEIRA, D. B.; SHIBATTA, O. A. Peixes como indicadores da qualidade ambiental do ribeirão Esperança, município de Londrina, Paraná, Brasil. Biota Neotropica, Campinas, v. 7, n. 1, p. 57-65, 2007.

WILLIS, E. O. The composition of avian communities in remanescent woodlots in southern Brazil. Papéis Avulsos de Zoologia, São Paulo, v. 33, n. 1, p. 1-25, 1979.

WILSON, D. E.; REEDER, D. Mammal species of the world: A taxonomic and geographic reference. 3. ed. Baltimore: The Johns Hopkins University Press, 2005.

ZAMPROGNO,C.;TEIXEIRA, R.L.Hábitos alimentares da lagartixa-de-parede Hemidactylus mabouia (Reptilia, Gekkonidae) da planície litorânea do norte do Espírito Santo, Brasil. Revista Brasileira de Biologia, São Carlos, v. 58, n. 1, p. 143-150, 1998.

ZOONOMEN. Zoological nomenclatural resource. Disponível em: <http://www.zoonomen.net/>. Acesso em: 17 out. 2007. 